\title{
Talimogene laherparepvec: review of its mechanism of action and clinical efficacy and safety
}

\author{
Steven S Raman ${ }^{1}$, Joel Randolph Hecht ${ }^{1}$ \& Emily Chan*,2 \\ ${ }^{1}$ David Geffen School of Medicine, University of California, Los Angeles, CA, 90095 USA \\ ${ }^{2}$ Amgen Inc., Thousand Oaks, CA, 91320 USA \\ *Author for correspondence: Tel.. +1 805313 0235; echan03@amgen.com
}

Intratumoral immunotherapy inhibits tumor growth by killing injected tumor cells, thus initiating local and systemic immune responses. Oncolytic viruses are a novel class of intratumoral immunotherapies that show promise for treating solid tumors. Talimogene laherparepvec is a first-in-class, genetically modified, herpes simplex virus type 1-based oncolytic immunotherapy approved for the local treatment of unresectable cutaneous, subcutaneous and nodal lesions in patients with melanoma recurrent after initial surgery. This review highlights the dual mechanism of action for talimogene laherparepvec (direct tumor cell lysis and stimulation of local response in tumor microenvironment and systemic immune response in distant metastases), summarizes key preclinical and clinical trials evaluating efficacy and safety of talimogene laherparepvec in melanoma, and describes studies ongoing in other solid tumors.

First draft submitted: 20 February 2019; Accepted for publication: 8 April 2019; Published online:

2 May 2019

Keywords: cancer immunology • cancer vaccines $\bullet$ vaccines-therapeutic

Intratumoral immunotherapy as a treatment for malignant tumors was first reported more than 100 years ago [1] and has recently been subject to a resurgence in interest [2]. The aim of intratumoral immunotherapy is to inhibit tumor growth by locally priming the human T-cell immune response against tumor-derived antigens for locoregional control in the injected site and to initiate a durable systemic clinical response in noninjected distant metastases through lymphatic and blood circulation [2]. The needle-based injection of intratumoral immunotherapy into multiple lesions can lead to the generation of a polyclonal immune response against antigens expressed across different cancer cell subclones, potentially providing a means to address intratumoral heterogeneity [2]. This approach avoids the need for manual antigen identification and isolation and reduces the delays and costs associated with exogenous production of a personalized vaccine while harnessing the patient's immune system to create a personalized treatment and response [2]. It may also reduce the potential for disease relapse and/or the development of treatment resistance associated with other tumor-targeted treatments, such as monoclonal antibodies [3].

Local intratumoral administration of immunostimulatory therapies enables high intratumoral bioavailability, decreasing the total required dose and minimizing systemic exposure to the therapy [2]. As a result, intratumoral administration can be more cost-effective than systemic administration of the same drug, with enhanced local efficacy and limited systemic adverse events (AEs). Importantly, the reduction in systemic AEs enables the use of combination therapy with additional mechanisms of action, which has the potential to further enhance treatment response and prevent the occurrence of treatment resistance, thus leading to long-term response. Repeated administration of intratumoral immunotherapy in combination with sequential biopsies enables identification of the intratumoral immune response and further supports personalization of treatment to prevent resistance. Initially, intratumoral immunotherapy was tested in melanoma because of the ease of accessibility to cutaneous, subcutaneous or palpable lesions; however, the emergence of additional methods, such as targeted interventional radiology (e.g., ultrasound or computed tomography [CT] guidance) [4] and novel drug delivery systems (e.g., nanodelivery) [5], that aid 


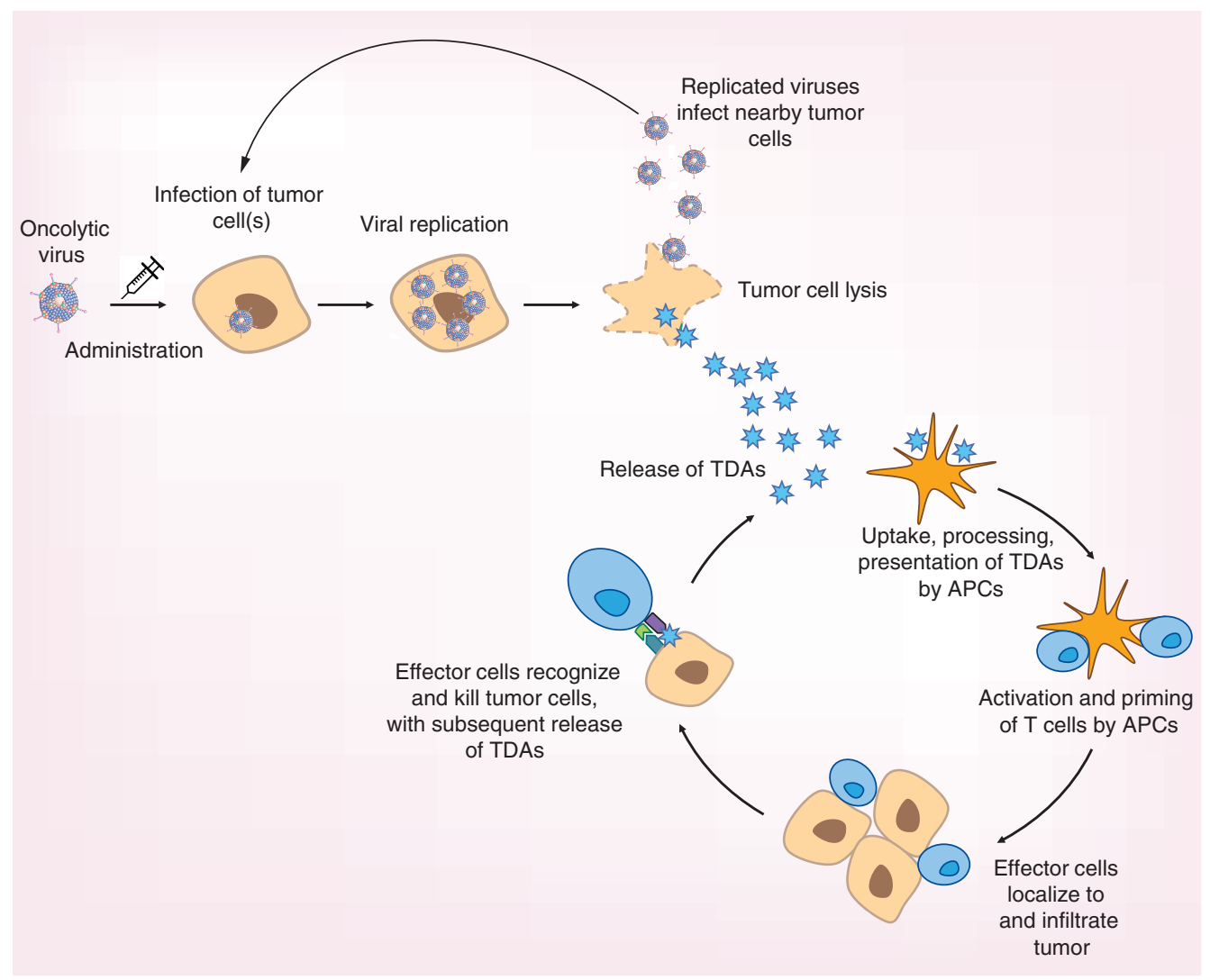

Figure 1. Viral oncolysis mechanism of action and immunogenic response to viral infection.

Reprinted with permission from Hamid O, Hoffner B, Gasal E, Hong J, Carvajal RD. Oncolytic immunotherapy: unlocking the potential of viruses to help target cancer. Cancer Immunol. Immunother. 66(10), 1249-1264 (2017). Creative Commons Attribution 4.0 International License: https://urldefense.proofpoint.com/v2/url?u=http-3A__creativ ecommons.org_licenses_by_4.0_\&d=DwICaQ\&c=Sexio4usKrYWFsrnxgjbcQ\&r=bCgdufakeXvf4UpXiQI-Ug\&m=rDoVAtPFI CAcvo3z7X22Wn4cmQI75FQfGkAmW9SOJpU\&s=ut8TEtvxVL4ZlaPT-wVTkDoY0_r0JjmX3gh9cMz1iZk\&e. APC: Antigen-presenting cell; TDA: Tumor-derived antigen.

in the delivery of immunotherapy to noncutaneous tumor sites may lead to future opportunities to administer intratumoral immunotherapy to a wide variety of tumor types [4].

Oncolytic viruses are a novel class of immunotherapy that provide promising results for the treatment of solid tumor types [6]. In 1904 the first case of virus-induced regression was reported in a patient with chronic myelogenous leukemia [7]. Since then, anecdotal evidence has alluded to a variety of viruses that can induce an antitumor response for a variety of different tumor types [8-14]. Native or modified viral vectors, targeted to infect tumor cells, replicate and cause tumor cell lysis (oncolysis) and release viral progenies that then infect neighboring tumor cells $[6,15]$. In addition, oncolytic viruses can trigger apoptosis of uninfected cancer cells and thus limit viral spread by eliminating the cellular mechanisms required for replication. Apoptosis may be triggered via transfer of empty virion capsids (i.e., the protein shell of the virus) [16] or by the binding of viral proteins to extracellular receptors [17]. Moreover, the natural affinity of oncolytic viruses for tumor cells can be further improved by genetic modification [18]. For example, deletion of the viral protein E1B55kd in an adenovirus (ONYX-015) demonstrated tumor-selective replication mainly caused by an increase in the export and expression of late viral RNAs [19-21]. This increase in viral tropism ultimately allows the oncolytic virus to spread through the tumor more efficiently, increasing the antitumor efficacy [18]. Oncolysis releases tumor-derived antigens that stimulate the immune system, priming T cells and resulting in the development of a tumor-specific local and systemic immune response (Figure 1) [6].

Genetically engineered HSV type 1 (HSV-1) are oncolytic viruses that are being evaluated in a wide range of solid tumors (e.g., melanoma, breast, head and neck, pancreatic, hepatocellular carcinoma) [6,22]. HSV-1 has a large, well-characterized genome that allows for the easy insertion of transgenes into the viral backbone [23]. Moreover, HSV-1 has the ability to remain as a viral episome (i.e., circular extrachromosomal DNA), thus reducing concerns 
Table 1. Genetic attributes of talimogene laherparepvec.

\begin{tabular}{|ll}
\hline Genetic attribute & Conferred function \\
\hline - HSV-1 JS1 strain & - Preferential and superior targeting of tumor cells \\
\hline - Deletion of ICP34.5 gene & - Attenuates the natural neurovirulence of HSV-1 \\
\hline - US11 gene & - Permits antigen presentation and allows for upregulation and earlier and increased expression of US11 \\
\hline - Insertion of GM-CSF cassette & $\begin{array}{l}\text { - Increased expression results in increased replication of ICP34.5-deleted HSV-1 in tumor cells without any loss of } \\
\text { tumor selectivity }\end{array}$ \\
\hline GM-CSF: Granulocyte-macrophage colony-stimulating factor; HSV-1: Herpes simplex virus type 1.
\end{tabular}

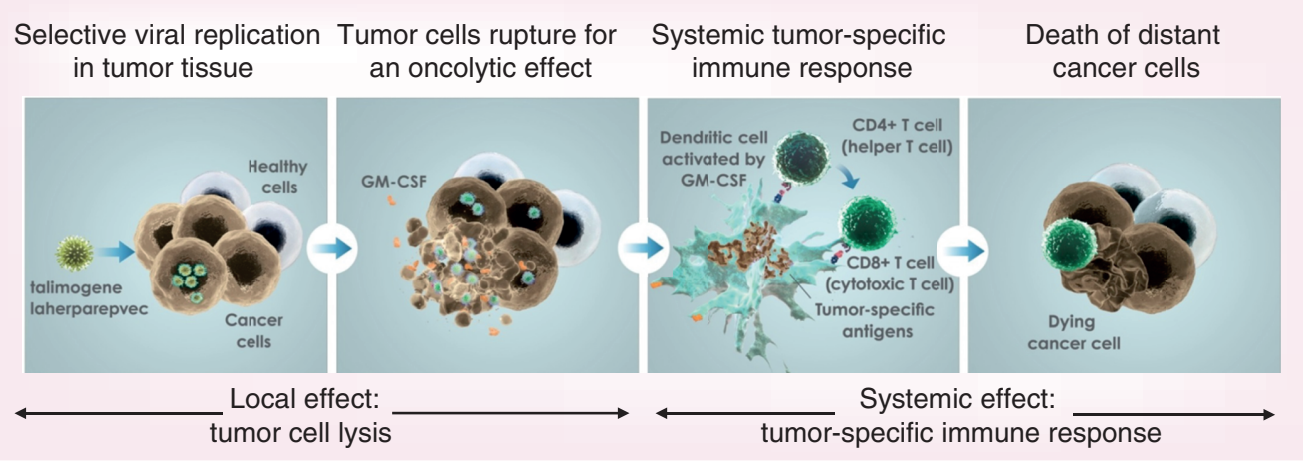

Figure 2. Talimogene laherparepvec mechanism of action. Image courtesy of Amgen Inc. Used with permission.

GM-CSF: Granulocyte-macrophage colony-stimulating factor.

for insertional mutagenesis [23]. Additionally, the general properties of HSV-1 make it amenable for use in the clinical setting with minimal risk for secondary transmission [24]; for example, the nature of the lipid bilayer makes it susceptible to lipid solvents and/or disinfectants [24]. Modified HSV-1 vectors also remain vulnerable to anti-HSV agents (e.g., acyclovir) [24].

Talimogene laherparepvec: the first US-approved oncolytic virus

Talimogene laherparepvec (T-VEC, TVEC; IMLYGIC ${ }^{\circledR}$; Amgen Inc., CA, USA) was the first oncolytic virus approved by the US FDA for the local treatment of unresectable cutaneous, subcutaneous and nodal lesions in patients with melanoma recurrent after initial surgery [25]. Talimogene laherparepvec has also been subsequently approved by the European Medicines Agency [26], the Australian Therapeutic Goods Administration [27], the Swiss Agency for Therapeutic Products [28] and by the Ministry of Health in Israel [29].

Talimogene laherparepvec is a live, attenuated HSV-1 that has been genetically modified (Table 1) to enable selective replication in tumor cells with a tolerable safety profile (Figure 2) [30]. Deletion of the ICP34.5 gene attenuates the natural neurovirulence of the virus [31,32], which enhances the preferential tumor-killing property of the HSV JS1 strain and diminishes infection of normal tissues, improving both safety and cancer specificity [30]. Furthermore, deletion of the ICP47 gene permits antigen presentation and allows for upregulation and earlier and increased expression of US11, resulting in increased replication of ICP34.5-deleted HSV-1 in tumor cells without any loss of tumor selectivity [30]. Last, insertion of a human granulocyte-macrophage colony-stimulating factor (GM-CSF) cassette allows for local expression to increase the activation of antigen-presenting cells [30].

\section{Preclinical studies}

In preclinical development, talimogene laherparepvec demonstrated activity in several tumor cell types, including melanoma cells. Two clinical strains of HSV-1 (BL1 and JS1) that were isolated from cold sores from otherwise healthy volunteers demonstrated preferential selectivity for tumor cells (versus normal cells) and superiority in killing tumor cells more quickly and at a lower concentration compared with the standard laboratory strain $17+$ [30]. Of the 
Table 2. Efficacy and safety of talimogene laherparepvec monotherapy in the treatment of melanoma.

\begin{tabular}{|c|c|c|c|}
\hline Reference & Melanoma type & $\begin{array}{l}\text { Talimogene laherparepvec dose, } \\
\text { comparative therapy }\end{array}$ & Key outcomes \\
\hline \multicolumn{4}{|l|}{ Phase I } \\
\hline $\begin{array}{l}\text { Hu et al. } \\
(n=26)\end{array}$ & $\begin{array}{l}\text { Refractory cutaneous or subcutaneous } \\
\text { metastases from breast, gastrointestinal } \\
\text { adenocarcinoma, malignant melanoma } \\
\text { or epithelia cancer of the head and neck }\end{array}$ & $\begin{array}{l}\text { Dose escalation: } \\
10^{6} \mathrm{pfu} / \mathrm{ml} \\
10^{7} \mathrm{pfu} / \mathrm{ml} \\
10^{8} \mathrm{pfu} / \mathrm{ml}\end{array}$ & $\begin{array}{l}\text { Safety: } \\
\text { AEs } \\
\text { - fever } \\
\text { - flu-like symptoms } \\
\text { - localized inflammation at injection site } \\
\text { Tolerability improved with initial } \\
\text { administration of } 10^{6} \mathrm{pfu} / \mathrm{ml}\end{array}$ \\
\hline \multicolumn{4}{|l|}{ Phase II } \\
\hline $\begin{array}{l}\text { Senzer et al. [34] } \\
(n=50)\end{array}$ & $\begin{array}{l}\text { Stage IIIC and IV unresectable } \\
\text { metastatic melanoma }\end{array}$ & $\begin{array}{l}10^{6} \mathrm{pfu} / \mathrm{ml} \text { then } 10^{8} \mathrm{pfu} / \mathrm{ml} \text { every } 2-3 \\
\text { wk for } 24 \text { treatments }\end{array}$ & $\begin{array}{l}\text { Efficacy: } \\
\text { All patients } \\
\text { - ORR, 26\% }(n=13) \\
\text { CR, } 16 \%(n=8) \\
\text { PR, } 10 \%(n=5) \\
\text { - } \text { DCR, }^{\dagger} 50 \% \\
\text { - 1-y survival, 58\% } \\
\text { Stage IV patients } \\
\text { - ORR, } 22.5 \%(n=9) \\
\text { - CR, } 15 \%(n=6) \\
\text { - PR, 7.5\% }(n=3) \\
\text { - 1-y survival, } 40 \%\end{array}$ \\
\hline \multicolumn{4}{|l|}{ Phase III } \\
\hline $\begin{array}{l}\text { Andtbacka et al. [22] } \\
(n=436)\end{array}$ & $\begin{array}{l}\text { Unresected stage IIIB, IIIC or IV } \\
\text { melanoma }\end{array}$ & $\begin{array}{l}10^{6} \mathrm{pfu} / \mathrm{ml}, 10^{8} \mathrm{pfu} / \mathrm{ml} \text { at week } 4 \text {, then } \\
10^{8} \mathrm{pfu} / \mathrm{ml} \text { every } 2 \mathrm{wk} \\
\text { (SC recombinant GM-CSF } 125 \mu \mathrm{g} / \mathrm{m}^{2} \\
\text { daily for } 14-\mathrm{d} / 28-\mathrm{d} \text { cycle) }\end{array}$ & $\begin{array}{l}\text { Efficacy: } \\
\text { Talimogene laherparepvec } \\
\text { - DRR, } ¥ 16.3 \%(n=48) \\
\text { - Median }(95 \% \text { CI) OS, } 23.3(19.5-29.6) \mathrm{mo} \\
\text { GM-CSF } \\
\text { - DRR, } 2.1 \%(n=3) \\
\text { - Median }(95 \% \text { Cl) OS, } 18.9(16.0-23.7) \mathrm{mo}\end{array}$ \\
\hline \multicolumn{4}{|c|}{$\begin{array}{l}\text { †Includes CR, surgical CR, PR and stable disease maintained for }>3 \text { months. } \\
\text { ¥Indicates } p<0.05 \text { for statistical difference between talimogene laherparepvec and the comparator arm. } \\
\text { AE: Adverse event; CR: Complete response; DCR: Disease control rate; DRR: Durable response rate (defined as CR and PR lasting } \geq 6 \text { mo continuously); GM-CSF: Granulocyte-macrophage } \\
\text { colony-stimulating factor; ORR: Overall response rate; OS: Overall survival; PR: Partial response; SC: Subcutaneous. }\end{array}$} \\
\hline
\end{tabular}

two isolated strains, JS1 had superior activity and remained more effective than strain $17+$ when the gene encoding ICP34.5 was deleted from both strains [30]. Moreover, deletion of the ICP47 gene from the JS1/ICP34.5- strain (i.e., JS1/ICP34.5-/ICP47-) resulted in further enhanced and prolonged tumor effects in mouse xenograft models compared with the JS1/ICP34.5- strain [30]. When genes encoding GM-CSF were inserted into the JS1/ICP34.5/ICP47-strain, the dose-related antitumor effect observed in the injected tumor was similar for strains with and without GM-CSF; however, in noninjected tumors, the dose-related antitumor effect was superior in the presence of the GM-CSF encoded strain (i.e., the current talimogene laherparepvec construct) [30].

\section{Clinical development in melanoma Clinical trials}

The majority of clinical evaluations of talimogene laherparepvec published to date have been conducted in patients with melanoma due to accessibility of lesions (Table 2 [22,33,34]). In a Phase I study, patients $(\mathrm{n}=26)$ with refractory cutaneous, subcutaneous, or nodal metastases from a range of tumor types (e.g., breast, gastrointestinal adenocarcinoma, malignant melanoma, epithelial cancer of the head and neck) were treated with escalating doses of talimogene laherparepvec $\left(10^{6}, 10^{7}\right.$ and $\left.10^{8} \mathrm{pfu} / \mathrm{ml}\right)$ to determine the safety profile, to assess biological activity and to determine a dosing schedule for future studies [33]. Patients who were initially seronegative for HSV had more marked side effects to talimogene laherparepvec than those who were seropositive [33]. Low-grade constitutional/flu-like symptoms were the most common AEs, and were more common and more pronounced in patients who were seronegative [33]. Inflammation at the injection site occurred in almost all patients, subsiding after a week in patients who were seropositive, persisting $\geq 2$ weeks in those who were seronegative [33]. All seronegative patients strongly seroconverted within 3 to 4 weeks of initial treatment with $10^{6} \mathrm{pfu} / \mathrm{ml}$ of talimogene laherparepvec [33]. After an initial dose of $10^{6} \mathrm{pfu} / \mathrm{ml}$, patients who were seronegative were able to avoid the extensive local inflammatory reactions that were previously observed with higher concentrations. GM-CSF-specific mRNA 
levels in samples taken from tumor lesions $48 \mathrm{~h}$ after administration of talimogene laherparepvec correlated with the dose administered and plateaued at concentrations of $10^{7} \mathrm{pfu} / \mathrm{ml}$ [33]. Therefore, a regimen consisting of an initial dose of $10^{6} \mathrm{pfu} / \mathrm{ml}$ followed by subsequent doses of $10^{8} \mathrm{pfu} / \mathrm{ml}$ administered every 2 to 3 weeks was determined to be the most appropriate approach for seronegative and seropositive patients [33].

In a Phase II trial, the safety and efficacy of talimogene laherparepvec $\left(4 \mathrm{ml}\right.$ of $10^{6} \mathrm{pfu} / \mathrm{ml}$ followed by $4 \mathrm{ml}$ of $10^{8} \mathrm{pfu} / \mathrm{ml}$ every 2 to 3 weeks for up to 24 treatments) in patients with stage IIIC or IV unresectable metastatic melanoma were evaluated [34]. In the 50 patients enrolled, the overall response rate (ORR) per Response Evaluation Criteria in Solid Tumors (RECIST) was 26\% (complete response [CR], 16\%; partial response [PR], 10\%) [34]. All seronegative patients had seroconverted by week 7 , and viral shedding at the injection site occurred in only 1 patient [34]. Tumor regression was seen in injected and distant lesions, including visceral lesions, and the overall 1 -year survival rate was $58 \%$ [34]. For those who achieved a CR or PR $(n=15)$, the 1 -year survival rate was 93\%. Additionally, treatment-related AEs were seen in $85 \%$ of patients, all of which were grade $1-2$; the most common treatment-emergent AEs observed were typically associated with mild flu-like symptoms [34].

The randomized, Phase III open-label OPTiM study evaluated talimogene laherparepvec compared with GMCSF alone (the transgene expressed by talimogene laherparepvec) in patients with unresected stage IIIB, IIIC or IV melanoma [22]. Patients $(n=436)$ were administered intratumoral talimogene laherparepvec (up to $4 \mathrm{ml}$ of $10^{6} \mathrm{pfu} / \mathrm{ml}$ followed by up to $4 \mathrm{ml}$ of $10^{8} \mathrm{pfu} / \mathrm{ml}$ at week 4 and then every 2 weeks) or subcutaneous recombinant GM-CSF $\left(125 \mu \mathrm{g} / \mathrm{m}^{2}\right)$ [22]. The durable response rate (DRR; defined as a CR or PR lasting $\geq$ 6 months continuously and beginning within 12 months of initiation of therapy) was significantly higher with talimogene laherparepvec (16.3\%) compared with GM-CSF (2.1\%; unadjusted odds ratio [OR], 8.9\% [95\% CI: 2.7-29.2\%]; $\mathrm{p}<0.001$ ) [22]. Treatment with talimogene laherparepvec also resulted in a median (95\% CI) overall survival (OS) of 23.3 (19.5-29.6) months compared with 18.9 (16.0-23.7) months with GM-CSF (hazard ratio [HR]: 0.79 [95\% CI: 0.62-1.00]; $\mathrm{p}=0.051$; Figure 3A) [22]. Both DRR (Figure 3B) and OS (Figure 3C) favored talimogene laherparepvec versus GM-CSF in patient subgroups (Supplementary Figure 1A-D).

The ORR was significantly higher with talimogene laherparepvec (26.4\%) than with GM-CSF $5.7 \%$; p $<0.001$ ) [22]. Of those who responded to talimogene laherparepvec therapy, prior to ultimately achieving an objective response, $54 \%$ experienced disease progression (i.e., the appearance of a new tumor or $>25 \%$ increase in total tumor area), highlighting the need to persist with therapy despite initial progressive disease [22]. For patients who experienced disease progression due to new lesions only, most progression was observed within 18 weeks of treatment; for those who experienced disease progression due to the growth of existing lesions (with or without development of new lesions), most progression occurred within 22 weeks of treatment [35]. Median (range) time to achieving a durable response was 3.1 (1.2-9.5) months for those without progression before response versus $5.8(1.3-10.6)$ months for those who had progression before response $(\mathrm{p}=0.004)$ [35]. Median $(95 \% \mathrm{CI})$ time to treatment failure was longer for talimogene laherparepvec (8.2 [6.5-9.9] months) than for GM-CSF (2.9 [2.8-4.0] months; HR: 0.42 [95\% CI: 0.32-0.54]) [22]. Furthermore, a $\geq 50 \%$ reduction was seen in $64 \%$ of injected lesions, $34 \%$ of noninjected nonvisceral lesions and $15 \%$ of noninjected visceral lesions, suggesting local injection could elicit an overall systemic response [35].

The response rate in patients with earlier-stage disease was higher than that observed in the OPTiM overall intentto-treat (ITT) population. In a subgroup of patients with stage IIIB/C $(n=131)$ or IVM1a $(n=118)$ melanoma (57.1\% of the OPTiM ITT population), DRR was higher in patients who received talimogene laherparepvec (25.2\%) compared with those who received GM-CSF (1.2\%; treatment difference [95\% CI], 24\% [17.0\%31.0\%]; $\mathrm{p}<0.0001$; Figure 3B) [22,36]. Additionally, the estimated 5-year survival rate for patients with an overall response was $78 \%$, suggesting that talimogene laherparepvec could potentially delay disease progression in this population. Of those with a durable response to talimogene laherparepvec $(n=41), 49 \%$ experienced disease progression before achieving a response [36]. Furthermore, OS also favored talimogene laherparepvec for patients with stage IIIB/C or IVM1a disease (Figure 3C) [22], and the estimated 12-, 24-, 36- and 48-month survival rates were all higher in the talimogene laherparepvec group compared with the GM-CSF group [36].

AEs were reported for $99 \%$ of patients receiving talimogene laherparepvec and $95 \%$ of those receiving GM-CSF; treatment-related grade 3 or 4 AEs occurred in 11 and 5\%, respectively [22]. AEs that occurred more frequently in the talimogene laherparepvec group versus the GM-CSF group were fatigue (50 vs 36\%), chills ( 49 vs $9 \%$ ), pyrexia ( 43 vs $9 \%$ ), nausea (36 vs 20\%), flu-like illness (30 vs $15 \%$ ) and injection-site pain (28 vs 6\%). AEs leading to discontinuation occurred in $4 \%$ of patients in the talimogene laherparepvec arm and $2 \%$ in the GM-CSF arm; disease progression was the most common reason for treatment discontinuation in either arm. 


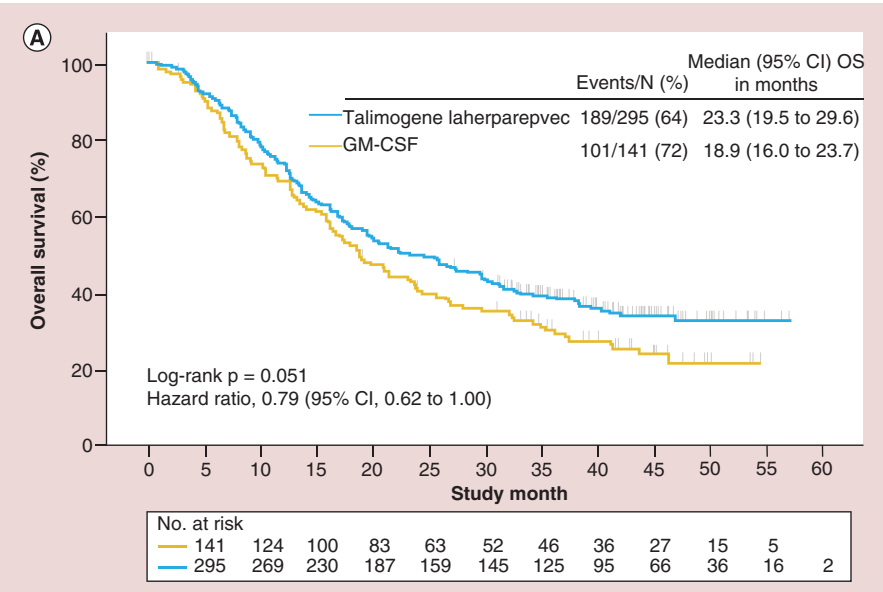

(B)

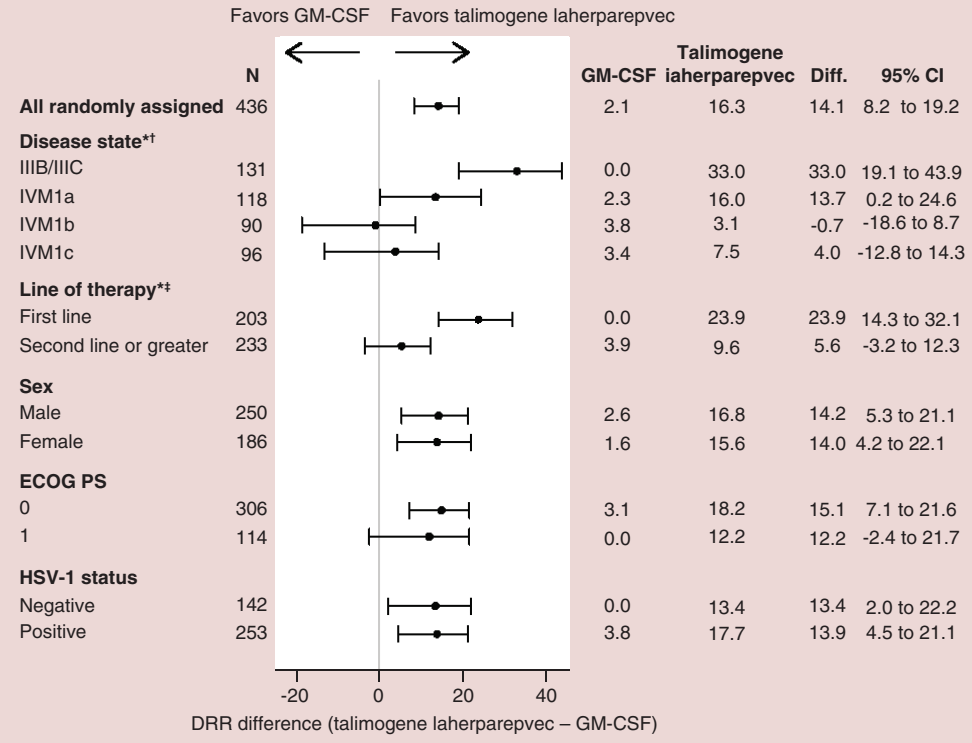

(C)

os

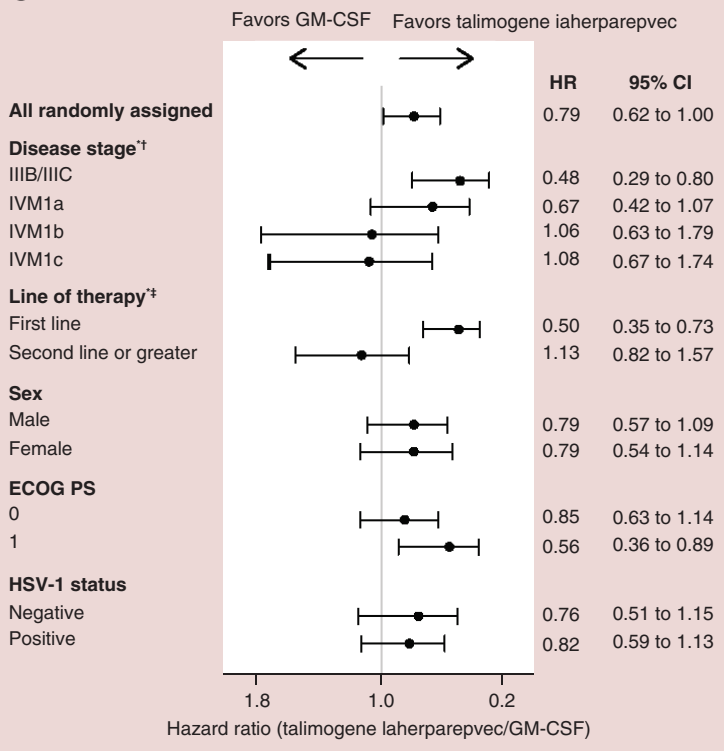

Figure 3. Efficacy outcomes with talimogene laherparepvec monotherapy. (A) Overall survival after talimogene laherparepvec administration. Outcomes for (B) durable response rate (DRR) and (C) OS by patient subgroups.

${ }^{*} p<0.001$ per Gail and Simon quantitative treatment by covariate interaction test (for DRR).

$\dagger 1$ patient in the talimogene laherparepvec arm had unknown disease stage.

$\$ 12$ patients in the GM-CSF arm and 4 in the talimogene laherparepvec arm had unknown ECOG status.

ECOG PS: Eastern Cooperative Oncology Group performance status; GM-CSF: Granulocyte-macrophage colony-stimulating factor; HR: Hazard ratio; HSV-1: Herpes simplex virus type 1; OS: Overall survival.

Reproduced with permission from Andtbacka $\mathrm{RH}$, Kaufman $\mathrm{HL}$, Collichio $\mathrm{F}$ et al. Talimogene laherparepvec improves durable response rate in patients with advanced melanoma. J. Clin. Oncol. 33(25), 2780-2788 (2015). ( ) (2015) American Society of Clinical Oncology. All rights reserved.

\section{Clinical administration \& handling}

Talimogene laherparepvec is classified in the USA as a biosafety level 1 agent [37], a level that is not known to consistently cause disease in healthy adults. To ensure optimal biosafety practice, and to minimize transmission of the virus to any close contacts, it is important for healthcare professionals preparing and/or administering the treatment to follow handling guidelines and to educate patients on infection control measures [38].

Talimogene laherparepvec is administered as an intratumoral injection into cutaneous, subcutaneous and/or nodal lesions that are visible, palpable, or detectable by ultrasound guidance [25]. The recommended dosing regimen is an initial total dose of up to $4 \mathrm{ml}$ of $10^{6} \mathrm{pfu} / \mathrm{ml}$ followed by up to $4 \mathrm{ml}$ of $10^{8} \mathrm{pfu} / \mathrm{ml}$ after 3 weeks, and then every 2 weeks [25]. The injection volume is based on lesion size and ranges from $\leq 0.1 \mathrm{ml}$ for lesions $\leq 0.5 \mathrm{~cm}$ to $\leq 4.0 \mathrm{ml}$ for lesions $>5 \mathrm{~cm}$ [25]. Larger lesions and lesions that have developed since the previous treatment are 

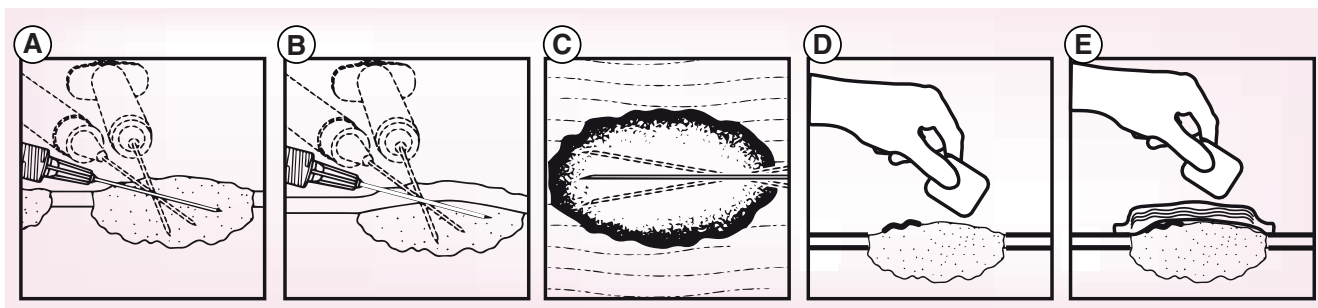

Figure 4. Talimogene laherparepvec injection procedure.

Before injection, the lesion and the surrounding areas should be cleaned with an alcohol swab and local anesthetic may be applied to the injection site or injected around the periphery of the lesion but not the lesion itself, if required. Injection administration for (A) cutaneous lesions, (B) subcutaneous lesions and (C) nodal lesions. A new needle is used for each lesion injected. (D) After injection the injection site and surrounding area should be swabbed with alcohol and an absorbent pad and dry occlusive dressing should be applied. (E) The exterior of the occlusive dressing should also be swabbed with alcohol.

\begin{tabular}{|c|c|c|}
\hline Location & Talimogene laherparepvec DNA detection n/N (\%) & Talimogene laherparepvec virus detection ${ }^{\dagger} \mathrm{n} / \mathrm{N}(\%)$ \\
\hline Blood & $59 / 60(98)$ & - \\
\hline Urine & $19 / 60(32)$ & - \\
\hline Injection site & $60 / 60(100)$ & $7 / 60(12)$ \\
\hline Occlusive dressing & $48 / 60(80)$ & 0 \\
\hline Orolabial region & $7 / 60(12)$ & 0 \\
\hline Anogenital region & $4 / 26(15)$ & $N / A^{\ddagger}$ \\
\hline Suspected herpetic lesions & $3 / 19(16)$ & 0 \\
\hline \multicolumn{3}{|c|}{$\begin{array}{l}† \text { Virus detection assays were only conducted on PCR-positive shedding samples. } \\
¥ \text { Results for swabs from the anogenital area were not available as of the data cutoff date; however, results were expected to be negative given the low level of DNA detected. } \\
\text { N/A: Not available. } \\
\text { Created using data from [39]. }\end{array}$} \\
\hline
\end{tabular}

given priority for injection [25]. Talimogene laherparepvec is a replication-competent attenuated virus (similar to a live-attenuated vaccine); therefore, healthcare providers who are immunocompromised or pregnant should not prepare or administer it; those who handle the product should wear appropriate personal protective equipment [25]. Procedures for virus injection are illustrated in Figure 4.

When administered intratumorally in the approved dose regimen to patients with stage IIIB or IVM1c melanoma, talimogene laherparepvec DNA was detected by qPCR in blood and urine in 98.3 and $31.7 \%$ of patients, respectively, with the highest levels of talimogene laherparepvec DNA detected during the second treatment cycle; no talimogene laherparepvec DNA was detected after the end of treatment (Table 3) [39]. All patients had detectable talimogene laherparepvec DNA at the injection site, but only $11.7 \%$ of patients had active virus (as measured by the $50 \%$ tissue culture infective dose $\left[\mathrm{TCID}_{50}\right]$ assay); typically, most positive samples were detected within the first two cycles of therapy [39]. Although $80 \%$ of patients had detectable talimogene laherparepvec DNA on the exterior of occlusive dressings, the $\mathrm{TCID}_{50}$ assay was negative in these, indicating that the occlusive dressing forms an effective barrier [39]. Of the 36 swabs from suspected herpetic lesions $(n=19)$ reported, only four swabs from three patients had detectable talimogene laherparepvec DNA; the $\mathrm{TCID}_{50}$ assays were negative [39]. Four close contacts, caregivers or healthcare providers reported a likely herpetic infection. None of the three individuals tested had any evidence of talimogene laherparepvec DNA [39]. To date, no transmission to healthcare providers or caregivers has been reported.

\section{Ongoing evaluation in melanoma trials}

At present, talimogene laherparepvec is being evaluated as neoadjuvant therapy in patients with resectable melanoma (ClinicalTrials.gov, NCT02211131) [40,41]. In this Phase II, multicenter, randomized, open-label study in patients with stage IIIB, IIIC or IVM1a melanoma eligible for complete surgical resection, patients were randomized to either talimogene laherparepvec followed by surgical resection of any remaining melanoma tumor lesions (Arm 1) or surgical resection alone (Arm 2) [40]. The primary endpoint was the effect of neoadjuvant talimogene laherparepvec 
plus surgery (Arm 1) versus surgery alone (Arm 2) on recurrence-free survival at 2 years [40]. Data from an interim analysis of this study have been previously presented [41].

The correlation between ORR and CD8+ cell density in patients treated with talimogene laherparepvec is also under evaluation (ClinicalTrials.gov, NCT02366195) [42]. In this Phase II, multicenter, single-arm study, the correlation between baseline intratumoral $\mathrm{CD}^{+}$cell density and outcomes was assessed in patients with unresected stage IIIB to IVM1c melanoma for whom surgery was not recommended [42]. Talimogene laherparepvec treatment was associated with a significant increase in $\mathrm{CD} 8^{+}$tumor-infiltrating lymphocytes in uninjected lesions, indicative of a systemic effect. The median increase in $\mathrm{CD}^{+}$cell density from baseline to week 6 in uninjected lesions was 2.4-fold ( $\mathrm{p}<0.0001$ ). In addition, substantial increases were observed in intratumoral density of granzyme B+ effector $\mathrm{CD}^{+} \mathrm{T}$ cells, memory $\mathrm{CD} 8^{+} \mathrm{T}$ cells, $\mathrm{CD}^{+} \mathrm{T}$ cells expressing checkpoint markers PD- 1 and CTLA- 4 , and granzyme $\mathrm{B}+$ natural killer cells but not macrophages [43]. The correlation between baseline intratumoral $\mathrm{CD} 8^{+}$cell density and outcomes is under evaluation.

\section{Combination trials with systemic immunotherapy \\ Checkpoint inhibitors}

The body's natural defense against cancer begins with T-cell recognition of a tumor antigen, followed by activation of $\mathrm{T}$ cells leading to an attack of the tumor antigen-bearing cells [44]. Normally, the immune system is regulated to prevent over-activation of $T$ cells through checkpoints that downregulate activation [44]. The cytotoxic $T$ lymphocyte antigen 4 (CTLA4) coinhibitory molecule on T cells inhibits activation upon interaction with antigen-presenting cells [44]. Concordantly, programmed death protein 1 (PD-1) is a checkpoint protein on T cells that, when bound to programmed death ligand 1 (PD-L1) on tumor cells (e.g., melanoma), dampens T-cell response [44]. Cancer cells have the ability to disrupt these checkpoints, allowing for uninhibited cell growth; for example, melanoma cells express PD-L1 and, thus, interfere with the body's normal immune function [44]. Immunotherapy with checkpoint inhibitors disrupts this process with antibodies that bind to the checkpoints on the cell surface receptors rendering them inactive, thus promoting the continued activation of immune cells [45]. The use of these inhibitors consequently augments the normal immune response of the body [46], and the inhibitors have been found to be effective in metastatic melanoma and other solid tumors [47-49].

\section{Rationale for combination therapy}

Combinations of immunotherapies should aim to increase the efficacy compared with each individual agent while minimizing the potential for additive toxicity. Checkpoint inhibitors and oncolytic viruses are one of many such combinations currently being explored; for example, a preclinical study with an oncolytic virus has demonstrated the ability to induce upregulation of PD-L1; thus a combination with anti-PD-1 antibodies would be expected to enhance the efficacy of the virus [46]. Moreover, introduction of an oncolytic virus, such as talimogene laherparepvec, can induce an immune response by altering the local tumor microenvironment from one that is not activated, or T-cell excluded, to one that is inflamed, causing T-cell infiltration [50]. These inflamed tumors would then be more susceptible to other immunotherapies, such as the checkpoint inhibitors, than they would have been before treatment with the oncolytic virus [50].

\section{Clinical trials of combination therapy in melanoma}

At present, talimogene laherparepvec has been evaluated in combination with checkpoint inhibitors in a variety of tumor types, including those with cutaneous/subcutaneous and/or nodal tumors, and further studies are ongoing. In a multicenter, open-label, single-arm, Phase Ib study (ClinicalTrials.gov, NCT02263508), the safety and efficacy of intratumoral talimogene laherparepvec (beginning in cycle 1) in combination with intravenous pembrolizumab (200 mg every 2 weeks beginning in cycle 3) was evaluated in patients with advanced melanoma [51]. Of the 21 patients enrolled, seven had received prior chemotherapy and four had received prior radiotherapy [51].

No dose-limiting toxicities (DLTs) were reported in the 21 patients evaluated [51]. Flu-like symptoms, including fatigue, fever, and chills, were the most commonly reported AEs [51]; this has been previously seen with talimogene laherparepvec [22] and pembrolizumab [52] monotherapies. Only one serious AE (grade 1 cytokine-release syndrome resulting in hospitalization) was considered to be possibly related to combination therapy; other serious AEs were considered related solely to pembrolizumab [51].

At the time of the primary analysis, the confirmed ORR (95\% CI) was 61.9\% (38.4-81.9\%) and the CR rate was $33.3 \%$ (14.6-57.0\%; Table 4) [51,53]. An initial increase in tumor size during talimogene laherparepvec monotherapy 
Table 4. Overall confirmed response rates for combination therapy.

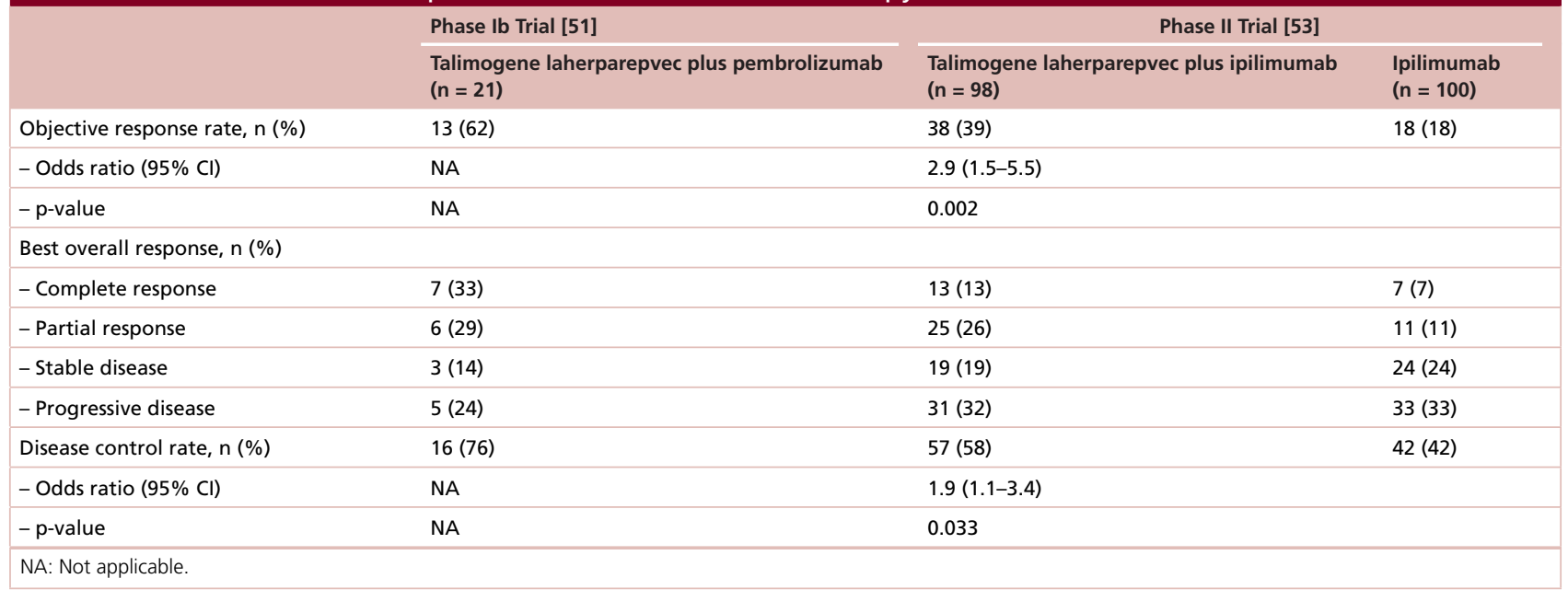

was not predictive of nonresponse to combination therapy [51]. In contrast to pembrolizumab monotherapy, the response to combination therapy was unrelated to baseline $\mathrm{CD} 8^{+} \mathrm{T}$-cell infiltration or IFN- $\gamma$ signature [51], suggesting that talimogene laherparepvec improves the efficacy of pembrolizumab. Immunohistochemical analysis of biopsies demonstrated that talimogene laherparepvec treatment increased the presence of CD8 ${ }^{+} \mathrm{T}$ cells in $75 \%$ of injected lesions and that an increase in $\mathrm{CD} 8^{+} \mathrm{T}$-cell density appeared to be associated with response to combination therapy [51]. Furthermore, tumor gene expression data demonstrated an elevation in CD8- $\alpha$ and IFN- $\gamma$ mRNA in injected and noninjected lesions after administration of talimogene laherparepvec [51].

As previously observed with talimogene laherparepvec monotherapy [35], combination therapy resulted in $>50 \%$ reduction in injected (82\%), noninjected nonvisceral (43\%) and noninjected visceral lesions $(33 \%)$ and was associated with a numerically better outcome than monotherapy [51]. In a subsequent follow-up efficacy analysis (data cut-off, June 11, 2018), with a median (range) follow-up time of 36.8 (1.4-39.6) months, two patients with a previous PR or stable disease changed to CR, thus improving the ORR to $67 \%$ (95\% CI: $43.0-85.4 \%$; $\mathrm{n}=14 / 21$ ) with a CR rate of $43 \%(n=9)$ [54]. Among the 14 responders, 12 remained in response at the data cutoff, including the nine patients with CR [54]. Median progression-free survival (PFS) and OS had not been reached as of the data cut-off; however, the 36-month PFS and OS rates were 53.6 and 71\%, respectively [54].

In a multicenter, open-label, randomized Phase II trial, the safety and efficacy of talimogene laherparepvec plus ipilimumab (3 mg/kg every 3 weeks) versus ipilimumab alone was evaluated in 198 patients with advanced, unresectable melanoma (NCT01740297) [53]. Overall, the ORR was significantly higher in patients who received combination therapy than in those who received ipilimumab monotherapy (39 vs 18\%; between-arm difference, 20.8\% (95\% CI: 7.5-33.2\%; $\mathrm{p}=0.002$; Table 4) [53]. The ORR was also significantly higher in the combination arm than the monotherapy arm in patients with stage IIIB/IIIC/IVM1a disease and numerically higher in patients with stage IVM1b or IVM1c disease (Figure 5) [53]. The median duration of response (DOR) was not evaluable at the time of publication of the interim analysis [53]; of patients who initially responded to therapy, $89 \%$ of those receiving combination therapy and $83 \%$ of those receiving ipilimumab monotherapy remained in response [53].

As previously observed with the pembrolizumab combination study [51], talimogene laherparepvec in combination with ipilimumab resulted in reduction in tumor burden for both injected and noninjected lesions, and the combination was associated with a greater tumor reduction than ipilimumab monotherapy in visceral lesions (52 vs $23 \%$, respectively) [53]. Median (95\% CI) progression-free survival was $8.2(4.2-21.5)$ months in the combination arm and 6.4 (3.2-16.5) months with ipilimumab alone (HR, 0.83 [95\% CI: 0.56-1.23]; $\mathrm{p}=0.35$ ); the HR for OS was 0.80 (95\% CI: 0.44-1.46) [53]. The incidence and nature of AEs was similar across treatment arms [53].

Additionally, in this study the incidence of pseudoprogression (i.e., apparent tumor progression that occurs in advance of eventual regression) was higher in patients treated with talimogene laherparepvec in combination with ipilimumab versus ipilimumab alone [55]. Overall, 39\% $(\mathrm{n}=38 / 98)$ of patients in the talimogene laherparepvec plus ipilimumab arm and $18 \%(\mathrm{n}=18 / 100)$ of patients in the ipilimumab alone arm had an OR; of these, seven patients $(7 / 38,18 \%)$ in the combination arm and one patient $(1 / 18,6 \%)$ in the ipilimumab arm had pseudoprogression, 


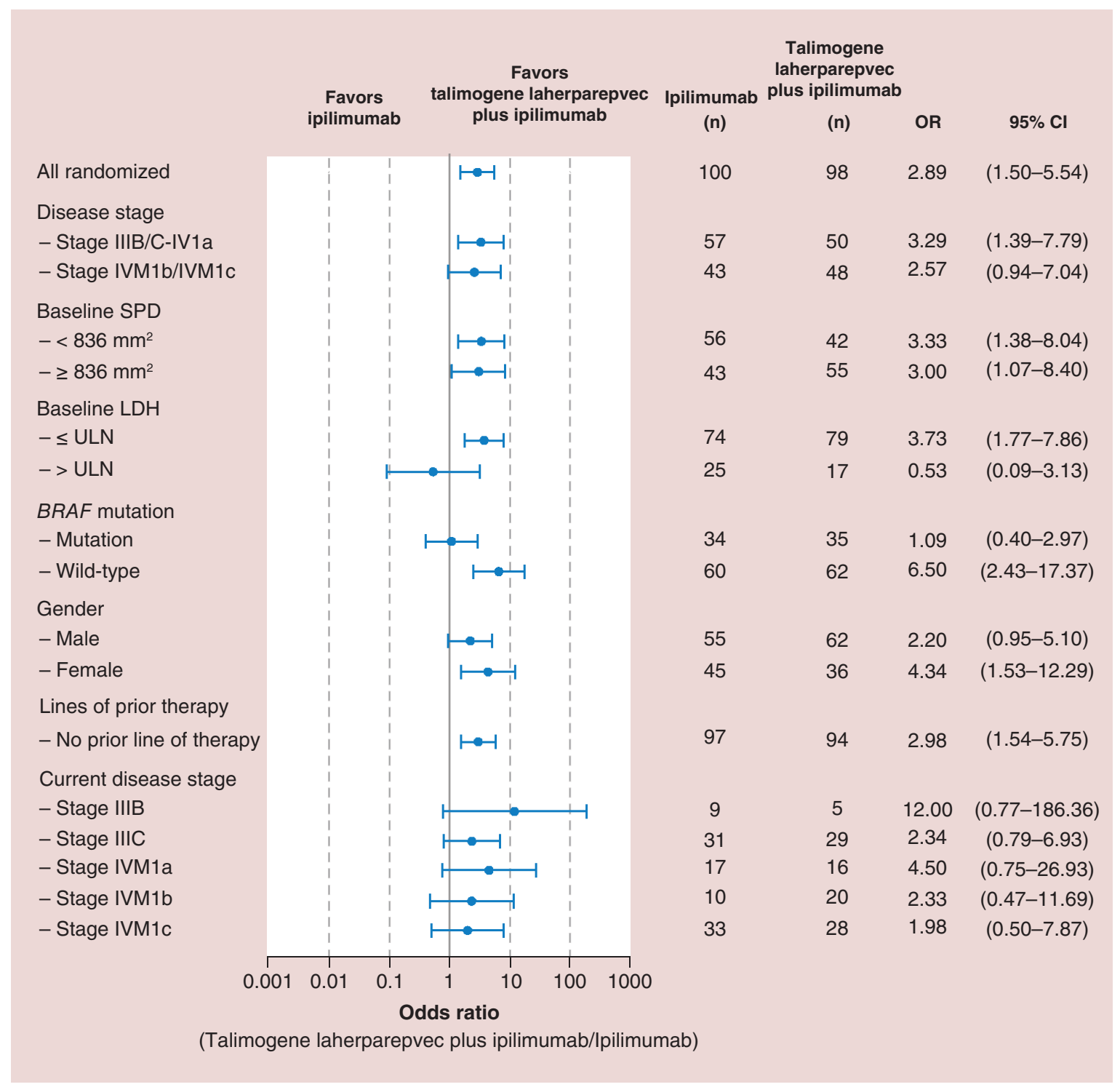

Figure 5. Objective response rate in patients with advanced unresectable metastatic melanoma receiving talimogene laherparepvec with ipilimumab combination therapy or ipilimumab alone.

LDH: Lactate dehydrogenase; OR: Odds ratio; SPD: Sum of the products of the two longest perpendicular diameters; ULN: Upper limit of normal.

Reproduced with permission from Chesney J, Puzanov I, Collichio F et al. Randomized, open-label Phase II study evaluating the efficacy and safety of talimogene laherparepvec in combination with ipilimumab versus ipilimumab alone in patients with advanced, unresectable melanoma. J. Clin. Oncol. 36(17), 1658-1667 (2018). (c) (2018) American Society of Clinical Oncology. All rights reserved.

respectively [55]. Most pseudoprogression occurred by the first assessment at week $12(88 \% ; n=7 / 8)$ and resolved by the following assessment at week $24(86 \% ; n=6 / 7)$ [55]. The incidence of pseudoprogression reported with combination therapy (18\%) was lower than that observed with talimogene laherparepvec monotherapy (48\%) [35] but was higher than the rates reported with other checkpoint inhibitor monotherapies $(\sim 10 \%)$ [56,57]. Overall, these results reinforce the use of immune-related response criteria (irRC) for evaluation of immunotherapies and support treatment with talimogene laherparepvec in combination with ipilimumab through the initial progression in melanoma [55]. 


\section{Clinical trials of combination therapy in other tumor types}

The safety of intratumoral talimogene laherparepvec in combination with intravenous pembrolizumab for recurrent or metastatic squamous cell carcinoma of the head and neck was evaluated in a multicenter, open-label, Phase Ib trial (MASTERKEY-232) [58]. Interim safety results $(\mathrm{n}=36)$ supported the combination regimen; one DLT (fatal arterial hemorrhage) was observed in 16 DLT-evaluable patients [59]. After this DLT was identified, a protocol amendment was added to exclude patients who were at high risk for arterial hemorrhage, such as those who had received reirradiation to a field that included the carotid arteries and those with tumors directly contacting or encasing a major blood vessel with ulceration and/or fungation onto the skin surface [58,59]. The most common treatment-emergent AEs were fever, dyspnea and fatigue [59]. Preliminary efficacy results showed the ORR (95\% CI) was $16.7 \%(6.4-32.8 \%)$ and the disease control rate was $38.9 \%(23.1-56.5 \%)$ [59].

Talimogene laherparepvec in combination with pembrolizumab has also been evaluated in an open-label, Phase II study of patients with metastatic sarcoma who had failed $\geq 1$ standard systemic therapy (ClinicalTrials.gov, NCT03069378) [60]. In the 20 patients enrolled, 19 were evaluable; four (21\%) had confirmed PR, nine (47\%) had stable disease and six (32\%) had disease progression per RECIST version 1.1 [60]. Two of the patients with stable disease had a 17 and $28.6 \%$, respectively, decrease in tumor burden at their first 8 -week interval scan [60]. Two patients (10\%) had grade 3 treatment-related AEs (fever from talimogene laherparepvec treatment, pneumonitis from pembrolizumab; $\mathrm{n}=1$ each); no grade $\geq 4$ treatment-related AEs were observed [60].

Lastly, talimogene laherparepvec is also being evaluated in pediatric patients with non-central nervous system tumors [61]. Approximately 18 pediatric patients are planned to be enrolled and treated with talimogene laherparepvec according to label dosing guidelines [61]. The primary outcome of the study is patient incidence of DLTs; secondary outcomes include ORR, DOR, time to response, time to progression, PFS and OS [61]. Results from this study had not been reported at the time of writing.

\section{Combination therapy in noncutaneous tumor types}

To date, talimogene laherparepvec is approved as an intratumoral injection for the local treatment of unresectable, cutaneous, subcutaneous and nodal lesions in patients with melanoma recurrent after initial surgery [25]. The safety and efficacy of other methods for intratumoral talimogene laherparepvec administration are being assessed in noncutaneous tumor types.

A multicenter, open-label, Phase $\mathrm{Ib} / \mathrm{II}$ trial is currently underway to evaluate the safety of intrahepatic injection of talimogene laherparepvec (using ultrasound/CT guidance), as a monotherapy or in combination with systemic pembrolizumab, for the treatment of patients with liver metastases from other solid tumors or primary hepatocellular carcinoma (HCC; MASTERKEY-318) [62]. Talimogene laherparepvec (initial administration of $10^{6} \mathrm{pfu} / \mathrm{ml}$, followed by $10^{7}$ or $10^{8} \mathrm{pfu} / \mathrm{ml}$ every 3 weeks) is being evaluated to determine the maximum tolerated volume and concentration when administered alone or in combination with pembrolizumab [63]. Initial results indicate that the maximum tolerated concentration of talimogene laherparepvec monotherapy in the cohort with liver metastases from select solid tumors is $10^{6} \mathrm{pfu} / \mathrm{ml}$, followed by $10^{8} \mathrm{pfu} / \mathrm{ml}$, mirroring the FDA-approved concentrations for intratumoral administration in patients with melanoma [64]. A second study (ClinicalTrials.gov, NCT03256344) is also ongoing to identify DLTs associated with intrahepatic talimogene laherparepvec in combination with intravenous atezolizumab in patients with triple-negative breast cancer or colorectal cancer with liver metastases [65]. The intrahepatic injection of liver tumors has also been evaluated with other oncolytic viruses.

Injection of liver tumors involves the use of cross-sectional contrast-enhanced imaging to confirm the target lesion of choice, avoiding benign liver lesions such as cysts and hemangiomas. The lesion should preferably be away from major central bile ducts, major blood vessels, the bowel or the liver surface. Using either a coaxial technique (placing a larger $20 \mathrm{G}$ needle to the edge of the target lesion and then placing a smaller $22 \mathrm{G}$ needle through that needle into the lesion) or a direct technique (placing the $22 \mathrm{G}$ needle directly into the target lesion), the needle is precisely guided in real time by ultrasound or intermittently by CT into the target lesion. The needle is directed to the inside edge of the deep portion of the lesion and injected with one fourth of the volume. The needle is then retracted and another fourth of the volume is injected proximally. The needle is then advanced to the two perpendicular quadrants of the mass and injected sequentially with one fourth of the volume. Using the coaxial technique, a separate biopsy needle gun may be advanced to obtain specimen from the lesion before the injection if necessary (see video in Supplement for additional information). The choice of where to inject intratumorally may vary based on the specific characteristics of the lesion. 
Table 5. Overview of other ongoing studies of talimogene laherparepvec.

\begin{tabular}{|c|c|c|c|c|}
\hline ClinicalTrials.gov Identifier & Phase & Title of study & Cancer type & Outcomes \\
\hline \multicolumn{5}{|l|}{ Monotherapy } \\
\hline $\begin{array}{l}\text { NCT02756845 } \\
(\mathrm{n}=18)\end{array}$ & 1 & $\begin{array}{l}\text { Study of talimogene laherparepvec in } \\
\text { children with advanced non-CNS tumors }\end{array}$ & Advanced non-CNS tumors & $\begin{array}{l}\text { - DLTs } \\
\text { - Treatment-emergent AEs } \\
\text { - Laboratory abnormalities } \\
\text { - ORR } \\
\text { - DOR } \\
\text { - TTR } \\
\text { - TTP } \\
\text { - PFS } \\
\text { - OS }\end{array}$ \\
\hline $\begin{array}{l}\text { NCT02366195 } \\
(\mathrm{n}=112)\end{array}$ & II & $\begin{array}{l}\text { Single-arm trial to evaluate the role of the } \\
\text { immune response to talimogene } \\
\text { laherparepvec in unresected melanoma }\end{array}$ & Unresected stage IIIb-IVM1c melanoma & $\begin{array}{l}\text { - Correlation between baseline } \\
\text { intratumoral CD8+ cell density and: } \\
\circ \text { ORR } \\
\circ \text { DRR } \\
\circ \text { DOR } \\
\circ \text { Changes in tumor burden } \\
\text { - ORR } \\
\text { - DOR }\end{array}$ \\
\hline $\begin{array}{l}\text { NCT02658812 } \\
(\mathrm{n}=35)\end{array}$ & II & $\begin{array}{l}\text { Talimogene laherparepvec in treating } \\
\text { patients with recurrent breast cancer that } \\
\text { cannot be removed by surgery }\end{array}$ & $\begin{array}{l}\text { Malignant chest wall neoplasm, } \\
\text { recurrent breast carcinoma, recurrent } \\
\text { inflammatory breast carcinoma, stage } \\
\text { IV breast cancer AJCC v6 and v7, stage } \\
\text { IV inflammatory breast carcinoma }\end{array}$ & $\begin{array}{l}\text { - ORR } \\
\text { - DCR } \\
\text { - PFS } \\
\text { - OS } \\
\text { - AEs }\end{array}$ \\
\hline $\begin{array}{l}\text { NCT03714828 } \\
(\mathrm{n}=28)\end{array}$ & II & $\begin{array}{l}\text { Study of talimogene laherparepvec in } \\
\text { patients with cutaneous squamous cell } \\
\text { cancer }\end{array}$ & $\begin{array}{l}\text { Squamous cell carcinoma, skin cancer, } \\
\text { keratoacanthoma, cutaneous tumor, } \\
\text { skin cancer, squamous cell, lesion skin }\end{array}$ & $\begin{array}{l}\text { - ORR } \\
\text { - AEs leading to discontinuation } \\
\text { - DOR } \\
\text { - DR } \\
\text { - TTP } \\
\text { - ORR } \\
\text { - CRR } \\
\text { - SAEs } \\
\text { - AEs }\end{array}$ \\
\hline $\begin{array}{l}\text { NCT02288897 } \\
(\mathrm{n}=225)\end{array}$ & III & $\begin{array}{l}\text { PV-10 vs chemotherapy or oncolytic viral } \\
\text { therapy for treatment of locally advanced } \\
\text { cutaneous melanoma }\end{array}$ & Cutaneous melanoma & $\begin{array}{l}\text { - PFS } \\
\text { - CR } \\
\text { - Duration of CR } \\
\text { - OS } \\
\text { - AEs }\end{array}$ \\
\hline $\begin{array}{l}\text { NCT02173171 } \\
(\mathrm{n}=340)\end{array}$ & NA & $\begin{array}{l}\text { Registry study for talimogene } \\
\text { laherparepvec }\end{array}$ & $\begin{array}{l}\text { Any tumor type eligible for treatment } \\
\text { with talimogene laherparepvec }\end{array}$ & $\begin{array}{l}\text { - Treatment-related AEs } \\
\text { - OS } \\
\text { - Use of subsequent anti-cancer } \\
\text { therapy }\end{array}$ \\
\hline $\begin{array}{l}\text { NCT02910557 } \\
(\mathrm{n}=920)\end{array}$ & IV & $\begin{array}{l}\text { Postmarketing prospective study of } \\
\text { melanoma patients treated with IMLYGIC }{ }^{\circledR} \\
\text { to characterize risk of herpetic infection }\end{array}$ & Melanoma & $\begin{array}{l}\text { - Incidence of herpetic infection in } \\
\text { patients, close contacts and } \\
\text { healthcare professionals during and } \\
\text { after treatment } \\
\text { - Incidence of AES/SAEs } \\
\text { - OS }\end{array}$ \\
\hline $\begin{array}{l}\text { NСТ03064763 } \\
(\mathrm{n}=18)\end{array}$ & I & $\begin{array}{l}\text { Study to evaluate the safety/efficacy of } \\
\text { T-VEC in Japanese subjects with } \\
\text { unresectable stage IIIB-IV malignant } \\
\text { melanoma }\end{array}$ & $\begin{array}{l}\text { Unresectable stage IIIB-IV malignant } \\
\text { melanoma }\end{array}$ & $\begin{array}{l}\text { - DLTs } \\
\text { - DRR } \\
\text { - OS }\end{array}$ \\
\hline $\begin{array}{l}\text { NCT02211131 } \\
(\mathrm{n}=150)\end{array}$ & II & $\begin{array}{l}\text { Efficacy and safety of talimogene } \\
\text { laherparepvec neoadjuvant treatment plus } \\
\text { surgery versus surgery alone for melanoma }\end{array}$ & $\begin{array}{l}\text { Completely resectable stage IIIB, IIIC or } \\
\text { IVM1a melanoma }\end{array}$ & $\begin{array}{l}\text { - Efficacy } \\
\text { - Overall response } \\
\text { - Safety }\end{array}$ \\
\hline $\begin{array}{l}\text { NCT03458117 } \\
(\mathrm{n}=20)\end{array}$ & 1 & T-VEC in non-melanoma skin cancer & $\begin{array}{l}\text { Non-melanoma skin cancer, basal cell } \\
\text { carcinoma, squamous cell carcinoma, } \\
\text { cutaneous lymphoma, Merkel cell } \\
\text { carcinoma }\end{array}$ & $\begin{array}{l}\text { - Local immune effects } \\
\text { - Tumor regression } \\
\text { - Systemic immune response } \\
\text { - AEs }\end{array}$ \\
\hline \multicolumn{5}{|c|}{$\begin{array}{l}\text { AE: Adverse event; BOR: Best overall response; CNS: Central nervous system; CR: Complete response; CRR: Complete response rate; DCR: Disease control rate; DFS: Disease-free } \\
\text { survival; DLT: Dose-limiting toxicity; DOR: Duration of response; DRR: Durable response rate; EBRT: External beam radiotherapy; MTD: Maximum tolerated dose; NA: Not available; ORR: } \\
\text { Objective response rate; OS: Overall survival; pCR: Pathological complete response; PFS: Progression-free survival; PR: Partial response; RR: Response rate; SAE: Serious adverse event; } \\
\text { TTP: Time to progression; TTR: Time to response; T-VEC: Talimogene laherparepvec. }\end{array}$} \\
\hline
\end{tabular}


Table 5. Overview of other ongoing studies of talimogene laherparepvec (cont.).

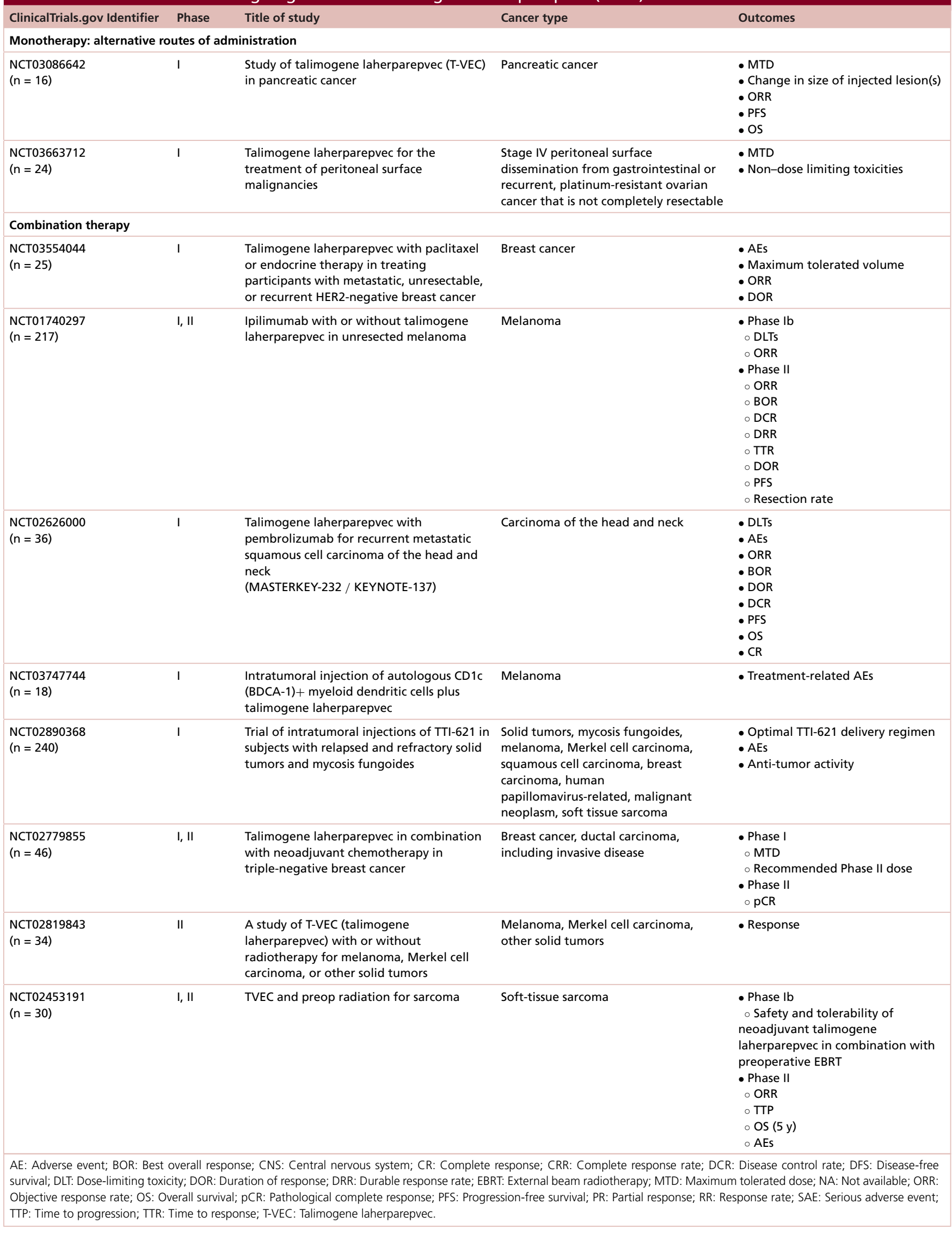


Table 5. Overview of other ongoing studies of talimogene laherparepvec (cont.).

\begin{tabular}{|c|c|c|c|c|}
\hline ClinicalTrials.gov Identifier & Phase & Title of study & Cancer type & Outcomes \\
\hline $\begin{array}{l}\text { NCT03069378 } \\
(\mathrm{n}=26)\end{array}$ & II & $\begin{array}{l}\text { A study of talimogene laherparepvec } \\
\text { (T-VEC) in combination with } \\
\text { pembrolizumab in patients with metastatic } \\
\text { and/or locally advanced sarcoma }\end{array}$ & Sarcoma & - Best ORR \\
\hline $\begin{array}{l}\text { NCT03088176 } \\
(\mathrm{n}=20)\end{array}$ & 1 & $\begin{array}{l}\text { Combining talimogene laherparepvec with } \\
\text { BRAF and MEK inhibitors in BRAF mutated } \\
\text { advanced melanoma }\end{array}$ & Melanoma, $B R A F$ gene mutation & $\begin{array}{l}\text { - DLTs } \\
\text { - PFS } \\
\text { - ORR } \\
\text { - Change in tumor burden } \\
\text { - TTR } \\
\text { - DOR }\end{array}$ \\
\hline $\begin{array}{l}\text { NCT02263508 } \\
(\mathrm{n}=713)\end{array}$ & III & $\begin{array}{l}\text { Pembrolizumab with or without } \\
\text { talimogene laherparepvec or talimogene } \\
\text { laherparepvec placebo in unresected } \\
\text { melanoma (KEYNOTE-034) }\end{array}$ & Melanoma & $\begin{array}{l}\text { - DLTs } \\
\text { - PFS } \\
\text { - OS } \\
\text { - AEs } \\
\text { - ORR } \\
\text { - BOR } \\
\text { - DRR ( } \geq 6 \mathrm{mo}) \\
\text { - DOR } \\
\text { - DCR } \\
\text { - CRR }\end{array}$ \\
\hline $\begin{array}{l}\text { NCT02978625 } \\
(\mathrm{n}=68)\end{array}$ & II & $\begin{array}{l}\text { Talimogene laherparepvec and nivolumab } \\
\text { in treating patients with refractory } \\
\text { lymphomas or advanced or refractory } \\
\text { non-melanoma skin cancers }\end{array}$ & Broad range & $\begin{array}{l}\text { - BOR } \\
\text { - DRR } \\
\text { - RR by cancer type } \\
\text { - RR by lesion (injected vs } \\
\text { noninjected) } \\
\text { - Frequency of curative surgery } \\
\text { - PFS } \\
\text { - OS } \\
\text { - AEs }\end{array}$ \\
\hline $\begin{array}{l}\text { NCT03555032 } \\
(n=15)\end{array}$ & I, II & $\begin{array}{l}\text { TITAN (Tumoral injection of talimogene } \\
\text { laherparepvec and isolated limb perfusion) }\end{array}$ & Melanoma and sarcoma & $\begin{array}{l}\text { - DLTs } \\
\text { - AEs } \\
\text { - CR } \\
\text { - PR }\end{array}$ \\
\hline $\begin{array}{l}\text { NCT02965716 } \\
(\mathrm{n}=64)\end{array}$ & II & $\begin{array}{l}\text { Talimogene laherparepvec and } \\
\text { pembrolizumab in treating patients with } \\
\text { stage III-IV melanoma }\end{array}$ & Melanoma & $\begin{array}{l}\text { - DRR } \\
\text { - CR } \\
\text { - PR } \\
\text { - RR } \\
\text { - ORR } \\
\text { - PFS } \\
\text { - OS }\end{array}$ \\
\hline \multicolumn{5}{|c|}{ Combination therapy: alternative routes of administration } \\
\hline $\begin{array}{l}\text { NCT03300544 } \\
(\mathrm{n}=21)\end{array}$ & 1 & $\begin{array}{l}\text { Talimogene laherparepvec, chemotherapy } \\
\text { and radiation before surgery in treating } \\
\text { patients with locally advanced or } \\
\text { metastatic rectal cancer }\end{array}$ & Rectal carcinoma & $\begin{array}{l}\text { - MTD } \\
\bullet \text { DLT } \\
\bullet \text { PCR } \\
\text { - DFS } \\
\text { - OS }\end{array}$ \\
\hline $\begin{array}{l}\text { NCT03256344 } \\
(\mathrm{n}=36)\end{array}$ & 1 & $\begin{array}{l}\text { A safety study of talimogene laherparepvec } \\
\text { combined with atezolizumab for } \\
\text { triple-negative breast cancer and colorectal } \\
\text { cancer with liver metastases }\end{array}$ & $\begin{array}{l}\text { Metastatic triple-negative breast cancer, } \\
\text { colorectal cancer }\end{array}$ & $\begin{array}{l}\text { - DLTs } \\
\text { - Treatment-emergent AEs } \\
\text { - ORR } \\
\text { - BOR } \\
\text { - DOR } \\
\text { - DRR } \\
\text { - PFS } \\
\text { - OS }\end{array}$ \\
\hline $\begin{array}{l}\text { NCT02509507 } \\
(\mathrm{n}=244)\end{array}$ & 1 & $\begin{array}{l}\text { Trial to evaluate the safety of talimogene } \\
\text { laherparepvec injected into liver tumors } \\
\text { alone and in combination with systemic } \\
\text { pembrolizumab }\end{array}$ & $\begin{array}{l}\text { Hepatocellular carcinoma, liver } \\
\text { metastases }\end{array}$ & $\begin{array}{l}\text { - DLTs } \\
\text { - ORR } \\
\text { - AEs } \\
\text { - Detectable virus levels }\end{array}$ \\
\hline \multicolumn{5}{|c|}{$\begin{array}{l}\text { AE: Adverse event; BOR: Best overall response; CNS: Central nervous system; CR: Complete response; CRR: Complete response rate; DCR: Disease control rate; DFS: Disease-free } \\
\text { survival; DLT: Dose-limiting toxicity; DOR: Duration of response; DRR: Durable response rate; EBRT: External beam radiotherapy; MTD: Maximum tolerated dose; NA: Not available; ORR } \\
\text { Objective response rate; OS: Overall survival; pCR: Pathological complete response; PFS: Progression-free survival; PR: Partial response; RR: Response rate; SAE: Serious adverse event } \\
\text { TTP: Time to progression; TTR: Time to response; T-VEC: Talimogene laherparepvec. }\end{array}$} \\
\hline
\end{tabular}


Table 5. Overview of other ongoing studies of talimogene laherparepvec (cont.).

\begin{tabular}{|c|c|c|c|c|}
\hline ClinicalTrials.gov Identifier & Phase & Title of study & Cancer type & Outcomes \\
\hline $\begin{array}{l}\text { NCT03597009 } \\
(n=24)\end{array}$ & I, II & $\begin{array}{l}\text { A study of nivolumab and intrapleural } \\
\text { talimogene laherparepvec for malignant } \\
\text { pleural effusion }\end{array}$ & $\begin{array}{l}\text { Malignant pleural effusion, stage IV } \\
\text { metastatic cancer, lung cancer }\end{array}$ & $\begin{array}{l}\text { - Phase I } \\
\circ \text { Treatment-related AEs } \\
\text { - Phase II } \\
\text { ○ Resolution of malignant pleural } \\
\text { effusion } \\
\circ \text { PFS } \\
\circ \text { OS } \\
\circ \text { RR } \\
\circ \text { Treatment-related AEs } \\
\circ \text { Average dyspnea score }\end{array}$ \\
\hline
\end{tabular}

AE: Adverse event; BOR: Best overall response; CNS: Central nervous system; CR: Complete response; CRR: Complete response rate; DCR: Disease control rate; DFS: Disease-free survival; DLT: Dose-limiting toxicity; DOR: Duration of response; DRR: Durable response rate; EBRT: External beam radiotherapy; MTD: Maximum tolerated dose; NA: Not available; ORR: Objective response rate; OS: Overall survival; pCR: Pathological complete response; PFS: Progression-free survival; PR: Partial response; RR: Response rate; SAE: Serious adverse event; TTP: Time to progression; TTR: Time to response; T-VEC: Talimogene laherparepvec.

Overall, the role of talimogene laherparepvec alone or as part of a combination regimen continues to be explored in a broad range of cancers, including pancreatic cancer, breast cancer, colorectal cancer with liver metastases, advanced non-CNS tumors, nonmelanoma skin cancers, metastatic squamous cell carcinoma of the head and neck, soft tissue sarcoma, liver tumors, Merkel cell carcinoma and rectal cancer (Table 5).

\section{Conclusion \& future perspective}

Talimogene laherparepvec is a novel oncolytic therapy with promising efficacy and a tolerable safety profile. The efficacy and safety observed with intratumoral talimogene laherparepvec in patients with melanoma resulted in this oncolytic therapy being approved in the United States, Europe, Australia, Switzerland and Israel. Recent studies have demonstrated the potential efficacy of talimogene laherparepvec in lesions that were not directly injected, including visceral lesions, and in combination with checkpoint inhibitors, thus indicating that talimogene laherparepvec may prove beneficial for the treatment of noncutaneous lesions. Moreover, when handled appropriately (i.e., use of personal protective equipment, proper cleaning of preparation and injection surfaces and instruments, timely changing of injection site dressings), the risks for secondary transmission and/or contamination are negligible. The exploration of various routes of intratumoral administration of talimogene laherparepvec in solid tumors, either alone or in combination with checkpoint inhibitors, is an active area of research.

\section{Acknowledgments}

The authors thank L Hohaia and M Johnson (Complete Healthcare Communications, LLC, PA, USA), whose work was funded by Amgen Inc., for medical writing assistance in the preparation of this manuscript.

Financial \& competing interests disclosure

SS Raman has nothing to disclose. JR Hecht reports receiving grants, personal fees and nonfinancial support from Amgen Inc., and has served as the principal investigator for the 20140299 (NCT03256344) and MASTERKEY-318 (NCT02509507) trials. E Chan is an employee of and stockholder in Amgen Inc. The authors have no other relevant affiliations or financial involvement with any organization or entity with a financial interest in or financial conflict with the subject matter or materials discussed in the manuscript apart from those disclosed.

\section{Data sharing}

Qualified researchers may request data from Amgen clinical studies. Complete details are available at the following: www.amge n.com/datasharing

\section{Author contributions}

All authors contributed to the conception/design of the work, the analysis and interpretation of the work, drafting of the manuscript, provided final approval to be published and agree to be accountable for all aspects of the work to ensure accuracy and integrity. 
Open access

This work is licensed under the Attribution-NonCommercial-NoDerivatives 4.0 Unported License. To view a copy of this license, visit http://creativecommons.org/licenses/by-nc-nd/4.0/

Supplementary data

A video abstract is available as an accompaniment to this paper. To view the supplementary data that accompany this paper and the video abstract please visit the journal website at: www.futuremedicine.com/doi/suppl/10.2217/imt-2019-0033

\section{Executive summary}

\section{Oncolytic viruses}

- Oncolytic viruses are a novel class of immunotherapy that provide promising results for the treatment of solid tumor types.

Talimogene laherparepvec mechanisms of action

- Talimogene laherparepvec is the first and only oncolytic virus approved by the US FDA for the local treatment of unresectable cutaneous, subcutaneous and nodal lesions in patients with melanoma recurrent after initial surgery.

- The proposed dual mechanisms of action of talimogene laherparepvec involve the direct lysis of tumor cells stimulating a local response in the tumor microenvironment and a concurrent systemic immune response via expression of granulocyte-macrophage colony-stimulating factor and presentation of tumor-derived antigens and subsequent activation of effector T cells in distant metastases.

Talimogene laherparepvec: clinical development

- Talimogene laherparepvec has demonstrated significant clinical benefit in patients with melanoma, both as a monotherapy and in combination with other immunotherapies.

- In addition to melanoma, talimogene laherparepvec is currently being evaluated in clinical trials of other solid tumor types.

- The safety and efficacy of other methods for intratumoral talimogene laherparepvec administration are being assessed in noncutaneous tumors such as liver metastases from solid tumors or primary hepatocellular carcinoma.

Talimogene laherparepvec: administration \& handling

- Talimogene laherparepvec is administered via intratumoral injection into cutaneous, subcutaneous and/or nodal lesions that are visible, palpable or detectable by ultrasound guidance; to minimize viral transmission, it is important for healthcare professionals preparing and/or administering the treatment to follow handling guidelines.

- The recommended dosing regimen for treatment of melanoma is an initial total dose of up to $4 \mathrm{ml}$ of $10^{6} \mathrm{pfu} / \mathrm{ml}$ followed by up to $4 \mathrm{ml}$ of $10^{8} \mathrm{pfu} / \mathrm{ml}$ after 3 weeks, and then every 2 weeks. The injection volume is based on lesion size and ranges from $\leq 0.1 \mathrm{ml}$ for lesions $\leq 0.5 \mathrm{~cm}$ to $\leq 4.0 \mathrm{ml}$ for lesions $>5 \mathrm{~cm}$.

- Before injection, the lesion and the surrounding areas should be cleaned with an alcohol swab and local anesthetic may be applied to the injection site, if required; after injecting the injection site, surrounding area and exterior of occlusive dressing should be swabbed with alcohol.

- To date, no transmission to healthcare providers or caregivers has been reported.

\section{References}

Papers of special note have been highlighted as: • of interest; $\bullet \bullet$ of considerable interest

1. Coley WB. The treatment of malignant tumors by repeated inoculations of erysipelas: with a report of ten original cases. Am. J. Med. Sci. 105(5), 487-510 (1893).

2. Marabelle A, Tselikas L, de Baere T, Houot R. Intratumoral immunotherapy: using the tumor as the remedy. Ann. Oncol. 28(suppl_12), xii33-xii43 (2017).

3. Varghese B, Widman A, Do J et al. Generation of CD8+ T cell-mediated immunity against idiotype-negative lymphoma escapees. Blood 114(20), 4477-4485 (2009).

4. Carpentier A, Metellus P, Ursu R et al. Intracerebral administration of CpG oligonucleotide for patients with recurrent glioblastoma: a Phase II study. Neuro Oncol. 12(4), 401-408 (2010).

5. Conniot J, Silva JM, Fernandes JG et al. Cancer immunotherapy: nanodelivery approaches for immune cell targeting and tracking. Front. Chem. 2, 105 (2014).

6. Hamid O, Hoffner B, Gasal E, Hong J, Carvajal RD. Oncolytic immunotherapy: unlocking the potential of viruses to help target cancer. Cancer Immunol. Immunother. 66(10), 1249-1264 (2017).

7. Dock G. The influence of complicating diseases upon leukaemia. Am. J. Med. Sci. 127(4), 563-592 (1904). 
8. Asada T. Treatment of human cancer with mumps virus. Cancer 34(6), 1907-1928 (1974).

9. Pasquinucci G. Possible effect of measles on leukaemia. Lancet 1(7690), 136 (1971).

10. Bluming AZ, Ziegler JL. Regression of Burkitt's lymphoma in association with measles infection. Lancet 2(7715), $105-106$ (1971).

11. Smith RR, Huebner RJ, Rowe WP, Schatten WE, Thomas LB. Studies on the use of viruses in the treatment of carcinoma of the cervix. Cancer 9(6), 1211-1218 (1956).

12. Toolan HW, Saunders EL, Southam CM, Moore AE, Levin AG. H-1 virus viremia in the human. Proc. Soc. Exp. Biol. Med. 119, 711-715 (1965).

13. Wheelock EF, Dingle JH. Observations on the repeated administration of viruses to a patient with acute leukemia. A preliminary report. N. Engl. J. Med. 271, 645-651 (1964).

14. Heinzerling L, Kunzi V, Oberholzer PA, Kundig T, Naim H, Dummer R. Oncolytic measles virus in cutaneous T-cell lymphomas mounts antitumor immune responses in vivo and targets interferon-resistant tumor cells. Blood 106(7), 2287-2294 (2005).

15. Liu TC, Galanis E, Kirn D. Clinical trial results with oncolytic virotherapy: a century of promise, a decade of progress. Nat. Clin. Pract. Oncol. 4(2), 101-117 (2007).

- Provides a review of the development history of oncolytic viruses and their use in cancer therapy.

16. Secchiero P, Flamand L, Gibellini D et al. Human Herpesvirus 7 induces CD4(+) T-cell death by two distinct mechanisms: necrotic lysis in productively infected cells and apoptosis in uninfected or nonproductively infected cells. Blood 90(11), 4502-4512 (1997).

17. Ullrich CK, Groopman JE, Ganju RK. HIV-1 gp120- and gp160-induced apoptosis in cultured endothelial cells is mediated by caspases. Blood 96(4), 1438-1442 (2000).

18. Howells A, Marelli G, Lemoine NR, Wang Y. Oncolytic viruses-interaction of virus and tumor cells in the battle to eliminate cancer. Front. Oncol. 7, 195 (2017).

19. Mullen JT, Tanabe KK. Viral oncolysis. Oncologist 7(2), 106-119 (2002).

20. Everts B, van der Poel HG. Replication-selective oncolytic viruses in the treatment of cancer. Cancer Gene Ther. 12(2), 141-161 (2005).

21. O'Shea CC, Johnson L, Bagus B et al. Late viral RNA export, rather than $\mathrm{p} 53$ inactivation, determines ONYX-015 tumor selectivity. Cancer Cell 6(6), 611-623 (2004).

22. Andtbacka RH, Kaufman HL, Collichio F et al. Talimogene laherparepvec improves durable response rate in patients with advanced melanoma. J. Clin. Oncol. 33(25), 2780-2788 (2015).

-• Reports the primary analysis results from the registrational OPTiM trial, the first Phase III study of talimogene laherparepvec in patients with melanoma.

23. Kaur B, Chiocca EA, Cripe TP. Oncolytic HSV-1 virotherapy: clinical experience and opportunities for progress. Curr. Pharm. Biotechnol. 13(9), 1842-1851 (2012).

24. Hoffner B, Iodice GM, Gasal E. Administration and handling of talimogene laherparepvec: an intralesional oncolytic immunotherapy for melanoma. Oncol. Nurs. Forum 43(2), 219-226 (2016).

-• Provides administration and handling guidelines for the use of talimogene laherparepvec in the clinical setting.

25. IMLYGIC $^{\circledR}$ (talimogene laherparepvec). Full Prescribing Information, Amgen Inc., Thousand Oaks, CA (2017).

26. IMLYGIC $^{\text {TM }}$ (talimogene laherparepvec). Summary of Product Characteristics, Amgen, London, UK (2016).

27. IMLYGIC $^{\text {TM }}$ (talimogene laherparepvec) Product Information. Amgen Inc. https://www.tga.gov.au/sites/def ault/files/auspar-talimogene-laherparepvec-160531-pi.pdf.

28. Imlygic ${ }^{\circledR}$, solution for injection (Talimogenum laherparepvecum). Swiss Agency for Therapeutic Products. https://www.swissmedic.ch/swissmedic/en/home/humanarzneimittel/authorisations/authorised-medicinal-products-with-new-active-su bstances/imlygic---injektionsloesung--talimogenum-laherparepvecum-.html.

29. Imlygic ${ }^{\circledR}$. https://www.old.health.gov.il/units/pharmacy/trufot/alonim/Rishum_8_87835118.pdf.

30. Liu BL, Robinson M, Han ZQ et al. ICP34.5 deleted herpes simplex virus with enhanced oncolytic, immune stimulating, and anti-tumour properties. Gene Ther. 10(4), 292-303 (2003).

31. Roizman B. The function of herpes simplex virus genes: a primer for genetic engineering of novel vectors. Proc. Natl Acad. Sci. USA 93(21), 11307-11312 (1996).

32. Wilcox DR, Longnecker R. The herpes simplex virus neurovirulence factor $\gamma 34$.5: revealing virus-host interactions. PLoS Pathog. 12(3), e1005449 (2016).

33. Hu JCC, Coffin RS, Davis CJ. A Phase I study of OncoVEX ${ }^{\mathrm{GM}-\mathrm{CSF}}$, a second-generation oncolytic herpes simplex virus expressing granulocyte macrophage colony-stimulating factor. Clin. Cancer Res. 12, 6737-6747 (2006).

34. Senzer NN, Kaufman HL, Amatruda T et al. Phase II clinical trial of a granulocyte-macrophage colony-stimulating factor-encoding, second-generation oncolytic herpesvirus in patients with unresectable metastatic melanoma. J. Clin. Oncol. 27(34), 5763-5771 (2009).

35. Andtbacka RH, Ross M, Puzanov I et al. Patterns of clinical response with talimogene laherparepvec (T-VEC) in patients with melanoma treated in the OPTiM Phase III clinical trial. Ann. Surg. Oncol. 23(13), 4169-4177 (2016). 
36. Harrington KJ, Andtbacka RH, Collichio F et al. Efficacy and safety of talimogene laherparepvec versus granulocyte-macrophage colony-stimulating factor in patients with stage IIIB/C and IVM1a melanoma: subanalysis of the Phase III OPTiM trial. Onco Targets Ther. 9, 7081-7093 (2016).

37. Amgen Inc. IMLYGIC ${ }^{\circledR}$ Material Safety Data Sheet. http://msds.amgen.com/ /media/amgen/repositorysites/msds-amgen-com/imlygicsds.ashx

38. McBride A, Valgus J, Parsad S, Sommermann EM, Nunan R. Pharmacy operationalization of the intralesional oncolytic immunotherapy talimogene laherparepvec. Hosp. Pharm. 53(5), 296-302 (2017).

39. Andtbacka RHI, Mehnert J, Nemunaitis JJ et al. Phase 2 trial evaluating biodistribution and shedding of talimogene laherparepvec (T-VEC) in patients (pts) with unresectable stages IIIB/IV melanoma. Mol. Ther. 25(5S1), 8 (2017).

40. ClinicalTrials.gov. Efficacy and safety of talimogene laherparepvec neoadjuvant treatment plus surgery versus surgery alone for melanoma. https://clinicaltrials.gov/ct2/show/record/NCT02211131?term=02211131\&rank=1.

41. Andtbacka RHI, Dummer R, Gyorki DE et al. Interim analysis of a randomized, open-label Phase 2 study of talimogene laherparepvec (T-VEC) neoadjuvant treatment (neotx) plus surgery (surgx) vs surgx for resectable stage IIIB-IVM1a melanoma (MEL). J. Clin. Oncol. 36(suppl), abstr 9508 (2018).

42. ClinicalTrials.gov. Single-arm trial to evaluate the role of the immune response to talimogene laherparepvec in unresected melanoma (TVEC-325). https://clinicaltrials.gov/ct2/show/study/NCT02366195?sect=X01256

43. Gogas H, Samoylenko I, Schadendorf D et al. Talimogene laherparepvec (T-VEC) treatment increases intratumoral effector T-cell and natural killer (NK) cell density in noninjected tumors in patients (pts) with stage IIIB-IVM1c melanoma: evidence for systemic effects in a Phase 2, single-arm study. Presented at: European Society for Medical Oncology 2018 Congress. Munich, GermanyOctober 19-23, 2018.

44. Furue M, Ito T, Wada N, Wada M, Kadono T, Uchi H. Melanoma and immune checkpoint inhibitors. Curr. Oncol. Rep. 20 (3), 29 (2018).

45. Bommareddy PK, Silk AW, Kaufman HL. Intratumoral approaches for the treatment of melanoma. Cancer J. 23(1), 40-47 (2017).

46. Marconcini R, Spagnolo F, Stucci LS et al. Current status and perspectives in immunotherapy for metastatic melanoma. Oncotarget 9(15), 12452-12470 (2018).

47. Hodi FS, O’Day SJ, McDermott DF et al. Improved survival with ipilimumab in patients with metastatic melanoma. N. Engl. J. Med. 363(8), 711-723 (2010).

48. Larkin J, Chiarion-Sileni V, Gonzalez R et al. Combined nivolumab and ipilimumab or monotherapy in untreated melanoma. N. Engl. J. Med. 373(1), 23-34 (2015).

49. Robert C, Schachter J, Long GV et al. Pembrolizumab versus ipilimumab in advanced melanoma. N. Engl. J. Med. 372(26), 2521-2532 (2015).

50. Haanen J. Converting cold into hot tumors by combining immunotherapies. Cell 170(6), 1055-1056 (2017).

51. Ribas A, Dummer R, Puzanov I et al. Oncolytic virotherapy promotes intratumoral T cell infiltration and improves anti-PD-1 immunotherapy. Cell 170(6), 1109-1119 (2017).

-• Reports the results from the Phase Ib MASTERKEY-265 study of talimogene laherparepvec in combination with pembrolizumab in patients with melanoma.

52. Ribas A, Hamid O, Daud A et al. Association of pembrolizumab with tumor response and survival among patients with advanced melanoma. JAMA 315(15), 1600-1609 (2016).

53. Chesney J, Puzanov I, Collichio F et al. Randomized, open-label Phase II study evaluating the efficacy and safety of talimogene laherparepvec in combination with ipilimumab versus ipilimumab alone in patients with advanced, unresectable melanoma. J. Clin Oncol. 36(17), 1658-1667 (2018).

-• Reports the results from a Phase II study of talimogene laherparepvec in combination with ipilimumab in patients with melanoma.

54. Long GV, Dummer R, Andtbacka RH et al. Follow-up analysis of MASTERKEY-265 Phase 1b (ph1b) study of talimogene laherparepvec (T-VEC) in combination (combo) with pembrolizumab (pembro) in patients (pts) with unresectable stage IIIB-IVM1c melanoma (MEL). Presented at: Society for Melanoma Research Congress 2018. Manchester, UK, October 24-27, 2018.

55. Chesney J, Puzanov I, Collichio F et al. Patterns of response with talimogene laherparepvec in combination with ipilimumab or ipilimumab alone in patients with metastatic, unresectable melanoma. Presented at: Society for Melanoma Research Congress. Manchester, UK, October 24-27, 2018.

56. Wolchok JD, Hoos A, O'Day $S$ et al. Guidelines for the evaluation of immune therapy activity in solid tumors: immune-related response criteria. Clin. Cancer Res. 15(23), 7412-7420 (2009).

57. Hodi FS, Hwu WJ, Kefford R et al. Evaluation of immune-related response criteria and RECIST v1.1 in patients with advanced melanoma treated with pembrolizumab. J. Clin. Oncol. 34(13), 1510-1517 (2016).

58. ClinicalTrials.gov. Talimogene laherparepvec with pembrolizumab for recurrent metastatic squamous cell carcinoma of the head and neck (MASTERKEY232 / KEYNOTE-137) (MASTERKEY232)

https://clinicaltrials.gov/ct2/show/NCT02626000?term=02626000\&cond=Cancer\&fund=23\&rank=1 
59. Harrington KJ, Kong AH, Mach N et al. Safety and preliminary efficacy of talimogene laherparepvec (T-VEC) in combination (combo) with pembrobrolizumab (Pembro) in patients (pts) with recurrent or metastatic squamous cell carcinoma of the head and neck (R/M HNSCC): a multicenter, Phase 1b study (MASTERKEY-232). J. Clin. Oncol. 26(suppl), abstr 6036 (2018).

60. Kelly CM, Bowler TG, Munhoz RR et al. A Phase II study of talimogene laherparepvec (T-VEC) and pembrolizumab in patients with metastatic sarcoma. J. Clin. Oncol. 36(suppl), abstr 11516 (2018).

61. ClinicalTrials.gov. Study of talimogene laherparepvec in children with advanced non CNS tumors. https://clinicaltrials.gov/ct2/show/NCT02756845?term=NCT02756845\&rank=1.

62. ClinicalTrials.gov. Trial to evaluate the safety oftalimogene laherparepvec injected into liver tumors alone and in combination with systemic pembrolizumab (MASTERKEY-318). https://clinicaltrials.gov/ct2/show/study/NCT02509507?term=02509507\&cond=Cancer\&fund=23\&rank=1

63. Hecht JR, Prat A, Pless M et al. A Phase 1b/2, multicenter, open-label trial to evaluate the safety of talimogene laherparepvec (T-VEC) injected into primary and metastatic liver tumors alone and in combination with pembrolizumab (pembro) (MASTERKEY-318). J. Clin. Oncol. 36(suppl), abstr TPS3105 (2018).

64. Hecht JR, Pless M, Cubillo A et al. Early safety from a Phase 1, multicenter, open-label clinical trial of talimogene laherparepvec (T-VEC) injected into liver tumors. J. Clin. Oncol. 36(suppl 4S), abstr 438 (2018).

- This abstract provides data on the use of talimogene laherparepvec in noncutaneous tumors types.

65. ClinicalTrials.gov. A safety study of talimogene laherparepvec combined with atezolizumab for triple negative breast cancer and colorectal cancer with liver metastases. https://clinicaltrials.gov/ct2/show/NCT03256344?term=20140299\&rank=1 